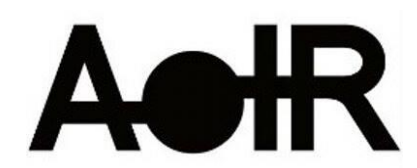

Selected Papers of \#AoIR2021:

The 22nd Annual Conference of the

Association of Internet Researchers

Virtual Event / 13-16 Oct 2021

\title{
AUSTRALIA'S BIG GAMBLE: THE NEWS MEDIA BARGAINING CODE AND THE RESPONSES FROM GOOGLE AND FACEBOOK
}

\author{
Francesco Bailo \\ University of Technology Sydney \\ James Meese \\ RMIT University \\ Edward Hurcombe \\ Digital Media Research Centre, Queensland University of Technology \\ Tama Leaver \\ Curtin University \\ Axel Bruns \\ Digital Media Research Centre, Queensland University of Technology \\ Dan Angus \\ Digital Media Research Centre, Queensland University of Technology \\ Belinda Barnet \\ Swinburne University of Technology
}

\section{Introduction: Content Platforms, News Media, and Government Regulation}

As news and media engagement preferences have shifted to online content platforms, so has the advertising market; this has fundamentally undermined the business model for conventional print journalism. More recently, a similar process has affected online news outlets as well: as a growing number of users discover news reports via search or social media rather than from visiting news sites directly, and as increasingly detailed previews of linked articles on such platforms decrease the likelihood that these users will click through to the full news article, advertisers prefer to run their ads on Google, Facebook, and other platforms rather than on the pages of the news sites themselves. According to recent analysis by the Australian Competition and Consumer Commission

Suggested Citation (APA): Bailo, F., J. Meese, E. Hurcombe, T. Leaver, A. Bruns, D. Angus, and B. Barnet. (2021, October). Australia's Big Gamble: The News Media Bargaining Code and the Responses from Google and Facebook. Panel presented at AolR 2021: The 22nd Annual Conference of the Association of Internet Researchers. Virtual Event: AolR. Retrieved from http://spir.aoir.org. 
(ACCC), online advertising now accounts for some $50 \%$ of total Australian advertising expenditure, and Google and Facebook alone capture nearly one third of that market (ACCC, 2019: 18).

Rather than acknowledging that, as Lotz (2021) has put it, "the business model is broken", news media representatives have increasingly sought to redress this substantial shift in the flow of advertising revenues by lobbying for regulatory change. Already, for instance, Google has struck a controversial deal with a group of French news publishers to pay them US\$76 million over three years (Rosemain, 2021), potentially preempting action under new European Union legislation designed to bring content platforms and news media to the negotiating table; while a court case about the copyright implications of Google news previews in Germany ended inconclusively (Frankfurter Allgemeine, 2020). Given the substantial financial, legal, and communicative resources available to major transnational content platforms such as Google and Facebook, however, such initiatives remain risky even if they have the backing of national governments, and may be tied up in the courts for many years.

\section{The Australian News Media Bargaining Code}

Responding rapidly to extraordinary developments in early 2021 , this panel examines the background, development, implementation, and consequences of the latest Australian regulatory intervention in the engagement between content platforms and domestic media organisations: the News Media Bargaining Code (NMBC). In response to the final report of the ACCC's Digital Platforms Inquiry (2019), the Australian federal government envisioned the NMBC as "a mandatory code of conduct to address bargaining power imbalances between Australian news media businesses and digital platforms, specifically Google and Facebook" (ACCC, 2021), and in April 2020 directed the ACCC to develop a draft code; following a period of consultation that saw substantial public relations campaigning from Google, Facebook, and other content platforms to question the aims and effectiveness of the proposed code (e.g. fig. 1), the NMBC bill was sent to federal Parliament in December 2020.

The way Aussies use Google is at
risk
Your search experience will be hurt by
new regulation

Dismiss

Learn more

Fig. 1: Warning message displayed to Australian users of Google Search as part of Google's campaign against the News Media Bargaining Code (Zhou, 2020)

Google and Facebook both threatened to remove their services from Australia, or remove Australian news content from their platforms, if the NMBC passed in its original form (Visentin \& Samios, 2021; Easton, 2020). Such threats were regarded by some of 
the NMBC's proponents as blatant attempts at "bullying" the Australian government to water down the Code (Lewis qtd. in New Daily, 2021), and in pushing ahead with the debate of the NMBC bill in the Australian Parliament the government essentially sought to call the platforms' bluff - yet in the morning of 18 February 2021, Facebook followed through on its threats and both removed all content from the Facebook pages of Australian news outlets (and from those of other actors mistakenly classified as providing news), and banned any domestic or international users from publishing or accessing any posts that contained links to Australian news sites (ABC News, 2021). The ban remained in force until 26 February, when urgent negotiations between Facebook and the Australian federal government produced a preliminary solution to the crisis. The Code finally became law on 2 March 2021.

This panel reviews these turbulent developments. Paper 1 opens the discussion by assessing the underlying patterns of news engagement on Facebook in Australia, thereby reviewing the evidence that was used to prompt the development of the News Media Bargaining Code. Paper 2 reviews the threats and tactics used by Google and Facebook to fight the NMBC, and the conditions which led both companies to claim they won their battle with the Australian Government. Paper 3 analyses the implementation, impact, and aftermath of the week-long Facebook news ban. Paper 4, finally, examines the implementation and impact of the News Media Bargaining Code to date, and assesses whether Google and Facebook have engaged in good faith in negotiations with Australia's media organisations. In combination, the four papers on this panel present a comprehensive and multifaceted picture of the News Media Bargaining Code, its context, and implications.

\section{References}

ABC News. (2021). Facebook Just Restricted Access to News in Australia: Here's What That Means for You. ABC News, 18 Feb. 2021. https://www.abc.net.au/news/2021-0218/facebook-news-ban-what-just-happened-post-zuckerberg/13166710

Australian Competition and Consumer Commission (ACCC). (2019). Digital Platforms Inquiry: Final Report. Canberra: Australian Competition and Consumer Commission. https://www.acc..gov.au/system/files/Digital\%20platforms\%20inquiry\%20\%20final\%20report.pdf

. (2021). News Media Bargaining Code: Project Overview.

https://www.accc.gov.au/focus-areas/digital-platforms/news-media-bargaining-code

Easton, W. (2020). An Update about Changes to Facebook's Services in Australia. Facebook Newsroom, 31 Aug. 2020. https://about.fb.com/news/2020/08/changes-tofacebooks-services-in-australia/

Frankfurter Allgemeine Zeitung. (2020). Google bleibt Prozess gegen VG Media erspart. Frankfurter Allgemeine Zeitung, 4 June 2020.

https://www.faz.net/aktuell/wirtschaft/google-bleibt-prozess-gegen-vg-media-erspart$\underline{16800970 . h t m l}$ 
Lotz, A. (2021). The Old News Business Model Is Broken: Making Google and Facebook Pay Won't Save Journalism. The Conversation, 29 Jan. 2021.

https://theconversation.com/the-old-news-business-model-is-broken-making-googleand-facebook-pay-wont-save-journalism-150357

New Daily, The. (2021). Google This: Tech Giant Threatens to Remove Search Engine from Australia over Media Code. The New Daily, 22 Jan. 2021.

https://thenewdaily.com.au/news/politics/2021/01/22/google-threats/

Rosemain, M., (2021). Exclusive: Google's \$76 Million Deal with French Publishers Leaves Many Outlets Infuriated. Reuters, 13 Feb. 2021.

https://www.reuters.com/article/us-google-france-copyright-exclusive-idUSKBN2AC27N

Visentin, L., \& Samios, Z. (2021). 'It's a Reality': Google Threatens to Stop Search in Australia Due to Media Code. Sydney Morning Herald, 22 Jan. 2021.

https://www.smh.com.au/politics/federal/google-threatens-to-disable-search-in-australiaif-media-code-becomes-law-20210122-p56w2h.html

Zhou, N. (2020). Google's Open Letter to Australians about News Code Contains 'Misinformation', ACCC Says. The Guardian, 17 Aug. 2020.

https://www.theguardian.com/technology/2020/aug/17/google-open-letter-australianews-media-bargaining-code-free-services-risk-contains-misinformation-accc-says 


\title{
Paper 1
}

\section{THE INSTITUTIONAL IMPACTS OF ALGORITHMIC DISTRIBUTION: FACEBOOK AND THE AUSTRALIAN NEWS MEDIA}

\author{
Francesco Bailo \\ RMIT University \\ James Meese \\ RMIT University \\ Edward Hurcombe \\ Digital Media Research Centre, Queensland University of Technology
}

\section{Background}

Social media platforms can adjust their recommender systems and preference some content over others. This has become an issue for news outlets, especially after Facebook changed its algorithm in January 2018 to preference content from family and friends over Facebook Pages. Even though the decision has had affected the business models of some companies more than others (Rashidian et al, 2019), the news sector has treated this as something of a watershed moment. Industry reports suggest that the news media are now favoring reader-focused business strategies over social media distribution (Logsdon, 2021). Alongside these changes, governments are introducing regulatory interventions that aim to introduce algorithmic transparency and, in some cases, force platforms to pay for news content (Meese, 2020; Myllylahti, 2018). These broadly contemporaneous developments underline the fact that the last few years have been a period of significant change in the publisher/platform relationship. However, scholars still struggle to adequately map the effects of algorithmic change. It is hard to identify the different ways that the news media outlets and news sectors as a whole, respond to platform decisions. It is equally difficult to assess how platforms treat news content.

\section{Literature Review and Methods}

Journalism scholars regularly base research projects on platform data and much of this work explores how social media platforms have changed journalism (Lewis and Molyneux, 2018). However, scholarship that explores the broader institutional impacts of social media platforms on journalism is only starting to emerge. As Rasmus Kleis Nielsen and Sarah Anne Ganter (2018, p. 1604) point out, too much of the existing journalism literature "has less to say about how news media adapt to the wider, ongoing, transformation of the environment in which they operate". Our paper contributes to this research agenda but takes a different methodological approach. Large datasets allow us to examine these structural relationships at scale. While this approach cannot delve into the nuances of specific decisions around distribution and posting, it allows us to see how an entire national media sector has interacted with 
digital platforms and in particular, Facebook, one of the most dominant sites for online news distribution in recent years.

We do this by drawing on various data sources to examine the Australian news media sector's relationship with Facebook from 2014 - 2020, with a particular focus on the January 2018 algorithm change. The analysis is supported by Facebook data $(2,082,804$ posts from Crowd Tangle) and external traffic data from 32 major Australian news outlets. This shows us how the Australia news media responded to these changes in the social media landscape. The addition of audience traffic data also allows us to see if news organizations turned to Google as an alternate distributor, following Facebook's algorithm changes. While our study cannot attribute causal inferences between algorithmic changes and the activities of news media outlets, our findings allow us to identify whole-of-sector trends and map future potential research sites. It also offers a much-needed empirical perspective on this period of transition and reveals how a national media sector engaged with digital platforms during a critical moment of change. We recognise that there are limitations to approaches that rely solely on 'big data' (boyd and Crawford, 2012; Puschmann, 2019), so we also refer to our previously published qualitative research (redacted) and desk research on occasion to provide further context to our findings.

\section{Findings}

We begin our analysis by focusing on Australian online news distribution trends to provide some wider context before discussing Facebook specifically. Our traffic data shows that only some outlets are heavily dependent on social traffic. Indeed, when we look at different news categories, Google search is often more important than social media for referrals. Social only plays a central referral role in the social news category. These findings provide some important context for our discussion of news performance on Facebook. Of course, Facebook referral traffic is still valuable as outlets want as many people viewing their content as possible, but these numbers suggest that most outlets across the country are not in a state of dependence.

Turning to on-platform performance, we can see that in terms of engagement, Australian news content experienced a clear period of success on Facebook before a reset occurred. In terms of interactions, digital native publications have had a mix of success and failure and print publications have faced a gradual decline. Conversely, the interactions of television and social news publications have collapsed.

Once we turned to comments an equally complicated picture emerged. We thought that news publishers might have worked to increase comments on their pages in response to the January 2018 algorithm change. Our hypothesis was partially confirmed but most of the growth in 2019 and early 2020 depends on the attention attracted by the pages of public service media which is consistently above our baseline over this period.

Another notable trend was the decline of news sharing. In a now common story for much of our dataset, there was a peak of activity around 2014 - 2016 followed by a collapse. While there was some resistance to this downward trend (particularly around 
early 2020 , perhaps attributable to the coronavirus), further declines occurred as the year went on.

\section{Analysis}

We draw on our findings to critically analyze the recent debate around the Australian News Media Bargaining Code, which forces platforms to pay for news content. The resulting furor around the reform saw Facebook ban news from Australia for a week before backing down. We argue that many outlets are not wholly dependent on Facebook and make active choices about where to distribute their content. Our position is supported by our findings, desk research and previous qualitative research (redacted). This challenges the entire logic of the law, which tries to link the declining economic sustainability of the Australian media sector to online platforms like Facebook and force an exchange of value. In contrast, we suggest that regulatory attention is more appropriate around concentration in the online advertising sector and wider antitrust concerns. Reform in these areas will provide downstream benefits for journalism (Meese, 2020). Alongside these efforts, a more concerted and rigorous commitment to publicly funding journalism is required across all jurisdictions.

\section{References}

boyd, d., \& Crawford, K. (2012). Critical question for big data: Provocations for a cultural, technological, and scholarly phenomenon. Information, Communication \& Society, 15(5): 662-679.

Kleis Nielsen, R., \& Ganter, S. A. (2018). Dealing with digital intermediaries: A case study of the relations between publishers and platforms. New Media \& Society, 20(4), 1600-1617.

Lewis, S. C., \& Molyneux, L. (2018). A decade of research on social media and journalism: Assumptions, blind spots, and a way forward. Media and Communication, 6(4), 11-23.

Meese, J. (2020). Journalism Policy across the Commonwealth: Partial Answers to Public Problems. Digital Journalism, 1-21. DOI: 10.1080/21670811.2020.1835514

Myllylahti, M. (2018). An attention economy trap? An empirical investigation into four news companies' Facebook traffic and social media revenue. Journal of Media Business Studies, 15(4), 237-253.

Puschmann, C. (2019). An end to the wild west of social media research: A response to Axel Bruns. Information, Communication \& Society, 22(11): 1582-1589.

Rashidian, N., Brown, P., Hansen, E., et al. (2018). Friend and foe: The platform press at the heart of journalism. Tow Centre for Digital Journalism. Available at: https://www.cjr.org/tow center reports/the-platform-press-at-the-heart-ofjournalism.php. 
Logsdon, B. (2021) 8 key takeaways from INMA's Media Subscriptions Summit 4.0. International News Media Association. Available at:

https://www.inma.org/blogs/conference/post.cfm/8-key-takeaways-from-inma-s-mediasubscriptions-summit-4-0 


\title{
Paper 2
}

\section{HOW GOOGLE AND FACEBOOK FOUGHT AUSTRALIA'S NEWS MEDIA BARGAINING CODE (AND WHY THEY THINK THEY WON)}

\author{
Tama Leaver \\ Curtin University
}

The July 2019 Digital Platforms Inquiry Report by the Australian Competition and Consumer Commission (ACCC) outlined a range of areas where Australian legislation did not address the realities of a digital world. One recommendation was that the government establish legislation to "address the imbalance in the bargaining relationship between leading digital platforms and news media businesses" (ACCC, 2019, p. 16). The ACCC tabled their draft to the Australian government in July 2020 as the News Media Bargaining Code (NMBC). This long abstract outlines a paper which examines the ways in which both Google and Facebook responded to the draft NMBC, focusing on the ways that both digital platforms threatened to remove part or all of their services in Australia rather than be subject to it, how Facebook briefly followed through on these threats, and how to NMBC was reshaped in light of them.

\section{The Draft Code}

The draft NMBC claimed to create a level playing field where Australian news companies could force Google and Facebook to negotiate a "fair" payment to link to, or show previews of, their news content. Some of the key features of this draft NMBC included (ACCC, 2020):

- Facebook and Google would be the (only) companies initially 'designated' (ie targeted).

- It applied to all Australian news organisations, regardless of size.

- Platforms would have 11 weeks to reach a mutually negotiated agreement, otherwise arbitration occurred (using 'final party' arbitration where both parties present a final offer, and an arbiter chooses between them).

- Platforms were required to give 28 days notice of any change to their algorithms that would impact on the ways Australian news appeared.

- Penalties could be ten million dollars, or $10 \%$ of the platform's annual Australian turnover.

Facebook and Google reacted very negatively to the draft NMBC, with their formal submissions arguing: that the algorithm change notifications would give certain news companies an unfair advantage; that charging for linking would break the underlying free nature of the web; and the arbitration model was completely one-sided (Facebook, 2020; Google, 2020).

\section{Google}

Google embarked on a nation-wide public relations campaign once the NMBC draft appeared. Most Australian Google properties were plastered with notifications asking 
users to read Google's proposal for 'a fair code'. Google deployed a video campaign featuring Australia comedian Greta Lee Jackson (Google Australia, 2020) who used the analogy of Google as a bus driver, who is forced to pay restaurants for delivering customers to them, and pay part of the running costs of restaurants.

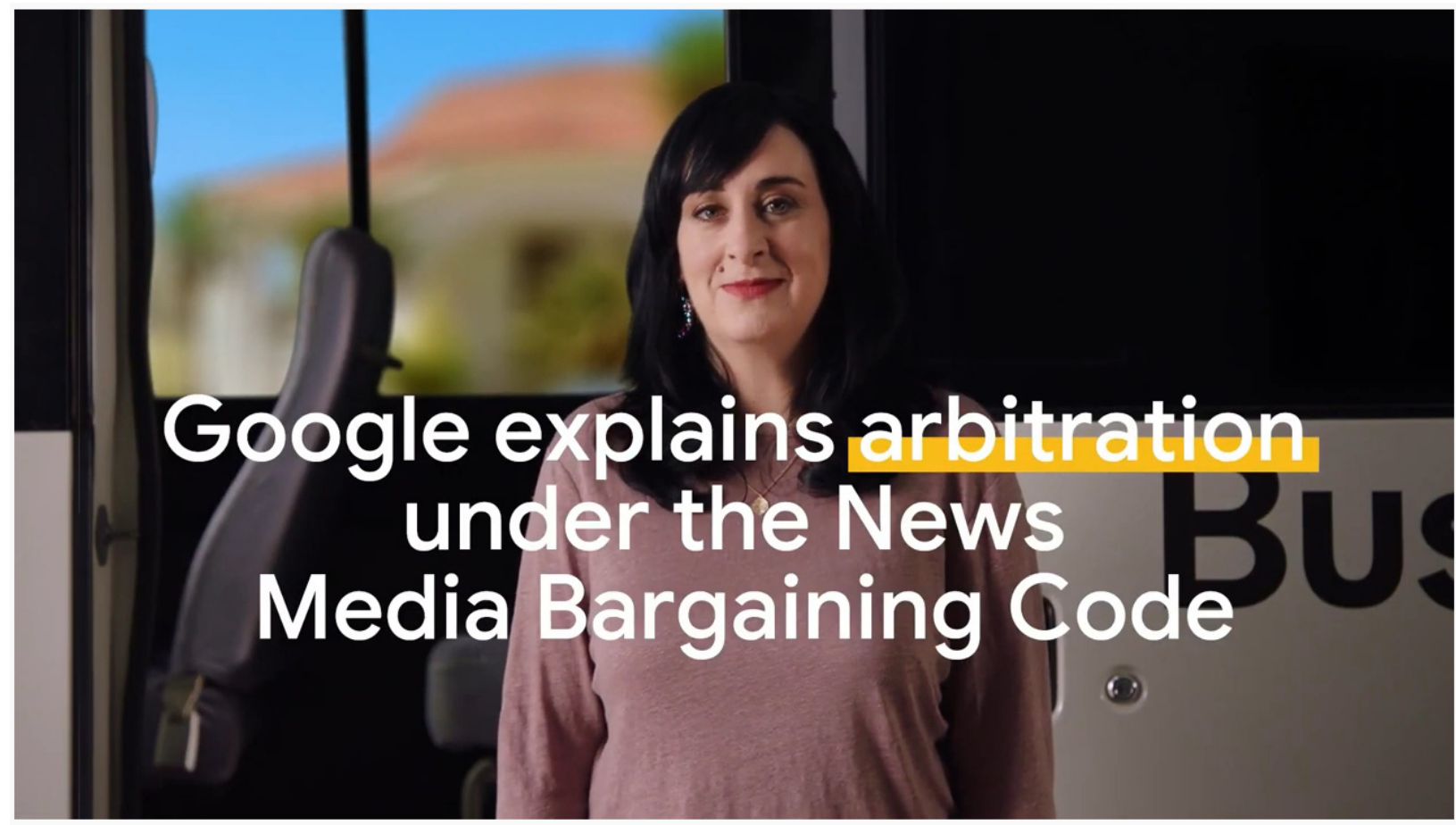

\#AFaircode

Google explains arbitration under the News Media Bargaining Code

10,408 views $\cdot 28$ Sept 2020

II 258 الو 161 SHARE $\equiv+$ SAVE $\ldots$

Figure 1. Screenshot of https://youtu.be/6lo01W3migk.

In early January 2021 Google ran an "experiment" which saw around 1\% of Australian users suddenly get older and less relevant material when searching for news. While ostensibly about testing Google's options for when the NMBC became law, it may also have been timed to warn just what Google was prepared to do. Doubling down, Mel Silva, Google's Australian Managing Director, gave public testimony about the company's position before a Senate inquiry which included the threat that if the NMBC wasn't amended, the company would have to withdraw Google search from Australia (Silva, 2021). Google also greatly amplified their appeal to the Australian public, with a video featuring Silva summarising Google's issues plastered across all of Google's Australian properties, with the video receiving more than 2.2 million views within 2 months (Google Australia, 2021). It grabbed global headlines, such as 'An Australia With No Google? The Bitter Fight Behind a Drastic Threat' (Cave, 2021).

\section{Facebook}

Facebook responded to the NMBC draft with threats; in a blog post Facebook's Australian Managing Director stated: "Assuming this draft code becomes law, we will reluctantly stop allowing publishers and people in Australia from sharing local and international news on Facebook" (Easton, 2020). Unlike Google whose notifications 
about the NMBC were inescapable, Facebook made no effort to warn Australian Facebook users. Most were shocked on 17 February 2021 when all traditional news and journalism had been removed from the platform, and attempting to share news was met with a notification that, "This post can't be shared".

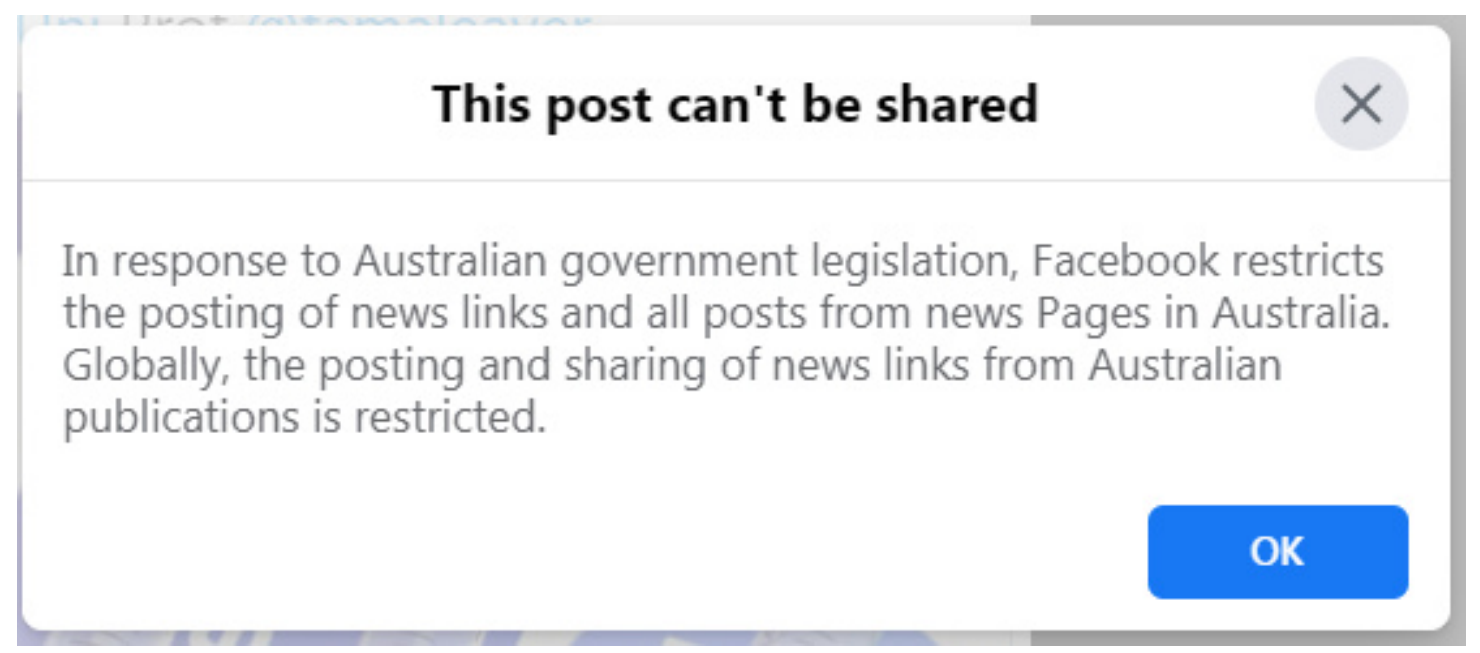

Figure 2. Facebook notification, 20 February 2021.

The Australian Prime Minister reacted angrily, publicly lamenting Facebook's choice to "unfriend Australia", adding their actions were "as arrogant as they were disappointing" (Snape, 2021). If this was part of a strategy to win Australian users, it backfired: their ban initially included a range of pages and services such as the Australia Bureau of Meteorology, emergency services pages, health care pages, and services providing information about the COVID-19 pandemic. Blocking these showed a complete lack of care or interest in Australian Facebook users, potentially opening the way to a tidal wave of misinformation filling the news void.

\section{Discussion \& Conclusion: Everyone Wins!}

Despite the public war of words, the Australian Treasurer met with Google and Facebook executives in February 2021 and negotiated concessions for both. Google ensured that existing deals and commitments would be tabled, modifying the way arbitration would work, while Facebook led the charge to extent the warning time before a company could be designated, and the time if had to respond. Importantly, it also received clarification that if they removed news altogether again, this would mean they were not subject to the NMBC at all. The biggest concession for both, though, was that the Treasurer clearly articulated that if they made enough deals before the NMBC was legislated, neither company would be designated by the Code. Thus Google never went through with their threat, and Facebook returned news to Australian users after just over a week. Both struck deals worth many millions of dollars with Australian news companies, and the genie of platforms paying for news was well and truly out of the bottle.

The Australian Government claimed to have won, as money flowed from the digital giants to Australian news companies. Google framed their victory as having saved the free web, and immediately launched their Australian Google News Showcase product. 
Facebook claimed to have defeated the extreme elements of the NMBC, framing their success as a win for business in Australia, but notably they never apologized to Australian users who got caught in the crossfire of Facebook's political battle.

\section{References}

ACCC. (2019). Digital platforms inquiry: Final report. https://www.accc.gov.au/focusareas/inquiries/digital-platforms-inquiry/final-report-executive-summary

ACCC. (2020, July 22). News media bargaining code: Draft legislation. https://www.accc.gov.au/focus-areas/digital-platforms/news-media-bargainingcode/draft-legislation

Cave, D. (2021, January 22). An Australia With No Google? The Bitter Fight Behind a Drastic Threat. The New York Times. https://www.nytimes.com/2021/01/22/business/australia-google-facebook-news$\underline{\text { media.html }}$

Easton, W. (2020, September 1). An Update About Changes to Facebook's Services in Australia. About Facebook. https://about.fb.com/news/2020/08/changes-to-facebooksservices-in-australia/

Facebook. (2020, August 28). Facebook response to the Australian Treasury Laws Amendment (News Media and Digital Platforms Mandatory Bargaining Code) Bill 2020. https://www.accc.gov.au/system/files/Facebook 0.pdf

Google. (2020, August 28). Draft News Media and Platforms Mandatory Bargaining Code: Submissions in Response. https://www.accc.gov.au/system/files/Google 0.pdf

Google Australia. (2020, September 28). Google explains arbitration under the News Media Bargaining Code. https://www.youtube.com/watch?v=6lo01W3migk

Google Australia. (2021, January 22). An update from Google on the News Media Bargaining Code. https://www.youtube.com/watch?v=dHypeuHePEI

Silva, M. (2021, January 22). Supporting Australian journalism: A constructive path forward. Google Australia. https://about.google/intl/ALL au/google-in-australia/jan-6letterl

Snape, J. (2021, February 18). Facebook unrepentant as Prime Minister dubs emergency services block "arrogant." ABC News. https://www.abc.net.au/news/202102-18/facebook-unrepentant-scott-morrison-dubs-move-arrogant/13169340 


\title{
Paper 3
}

\section{FACEBOOK'S AUSTRALIAN NEWS BAN: THREAT, IMPACT, AND AFTERMATH}

\author{
Axel Bruns \\ Digital Media Research Centre, Queensland University of Technology \\ Dan Angus \\ Digital Media Research Centre, Queensland University of Technology
}

\section{Introduction: Threats Made and Threats Fulfilled}

In late August 2020, As the Australian Competition and Consumer Commission (ACCC) and the Australian federal government outlined their plans for a News Media Bargaining Code (NMBC) that would force Facebook and other major online platforms to negotiate with Australian media organisations on payments for hosting their content, Facebook spoke out publicly against the proposed legislation - and its threat could not have been clearer. In a Facebook Newsroom post authored by the company's Managing Director for Australia and New Zealand, Will Easton, the company stated that

Assuming this draft code becomes law, we will reluctantly stop allowing publishers and people in Australia from sharing local and international news on Facebook and Instagram. (Easton, 31 Aug. 2020)

Importantly, as Australian commentators noted at the time (Meade, 2020), the company first briefed international media such as the New York Times (Wakabayashi \& Isaac, 2020) rather than Australian journalists about this move; this was understood by media analysts as indicating that "Facebook's main concern was that the mandatory code set an 'international precedent"' (Meade, 2020) and that Facebook was therefore prepared to set its own precedent with a firm response to the Australian legislation in order to deter governments and regulators elsewhere from implementing their own variations on the News Media Bargaining Code.

Australian media and government representatives remained sceptical about Facebook's willingness to follow through on this threat, however; a Nine Entertainment spokesperson described Facebook's response as "strange" (Meade, 2020), and Australian Treasurer Josh Frydenberg said that "Australia makes laws that advance our national interest and we won't be responding to coercion or heavy-handed tactics" (Blackiston, 2020). Industry responses, including that by ACCC Chair Rod Sims, also frequently cited the 2020 Digital News Report, which demonstrated the importance of Facebook as a news discovery mechanism for Australians: "39\% of Australians use Facebook for general news, and 49\% use Facebook for news about COVID-19", Sims pointed out (in Blackiston, 2020). 
Yet this arguably mistakes the importance of news on Facebook to Australians and the importance of news on Facebook to Facebook itself: while many Australians may indeed use Facebook to find out about the news, this does not mean that such news discovery constitutes a major part of everything else that Australians do on Facebook; Easton may well be correct when he claims in Facebook's own statement that

the ACCC presumes that Facebook benefits most in its relationship with publishers, when in fact the reverse is true. News represents a fraction of what people see in their News Feed and is not a significant source of revenue for us. (Easton, 2020)

Following through on its threat to remove news from the Australian Facebook altogether was always a live option for Facebook, therefore, however inconceivable or technically difficult it may have seemed to Australian policy-makers. And on 18 February 2021, as the Australian government moved forward with its NMBC legislation, the company did just that: all existing content disappeared from the Facebook pages of Australian news outlets (fig. 1), and Australian users seeking to access any Facebook posts from Australian or international news sources, as well as international users seeking to access Australian news posts on Facebook, encountered Facebook error messages (fig. 2). Finally, any attempts by ordinary Facebook users anywhere in the world to share Australian news links themselves were also blocked (fig. 3).

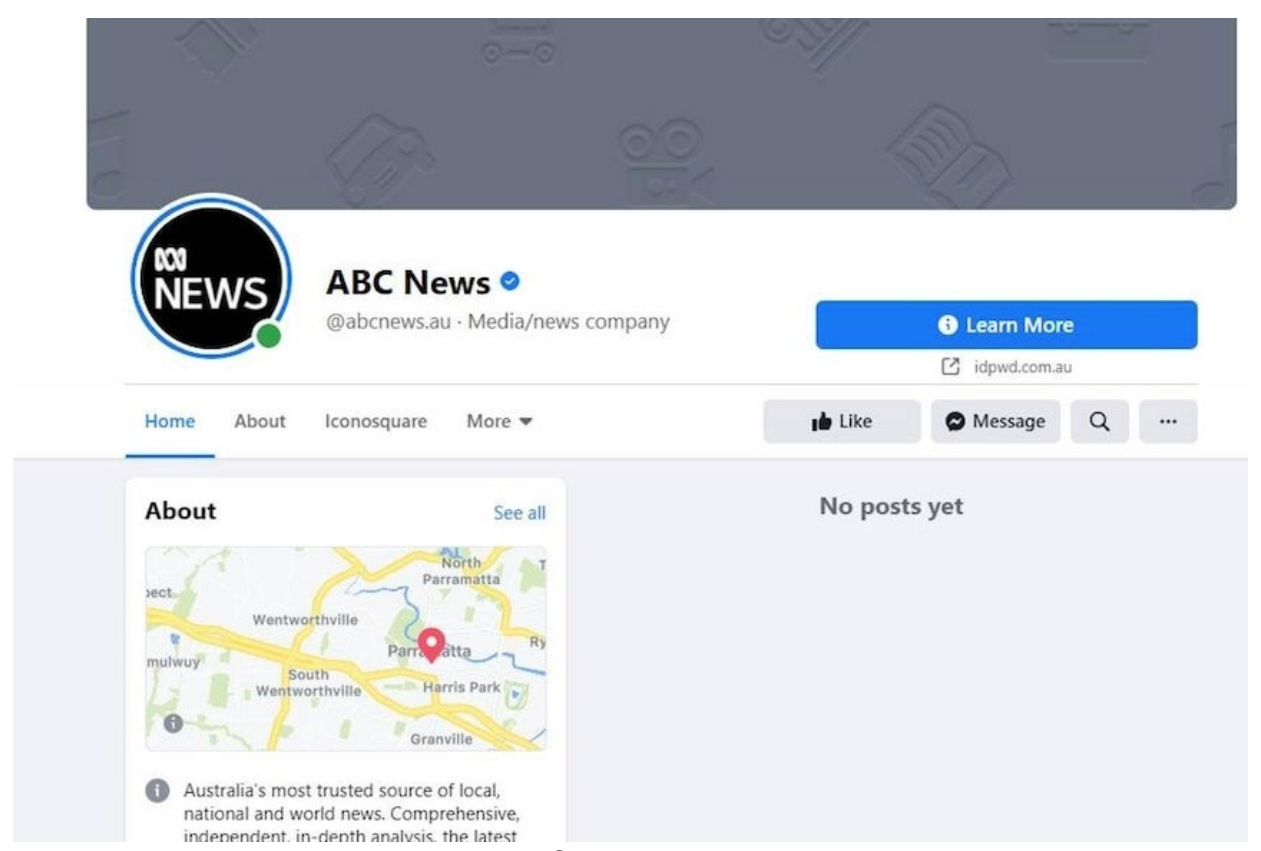

Fig. 1: The Facebook page of leading Australian public media outlet $A B C$ News during the news ban, showing the temporary disappearance of all previously posted news from the page (ABC News, 2021) 


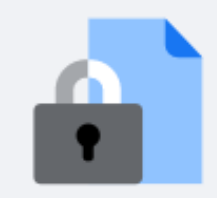

This content isn't available at the moment

When this happens, it's usually because the owner only shared it with a small group of people or changed who can see it, or it's been deleted.

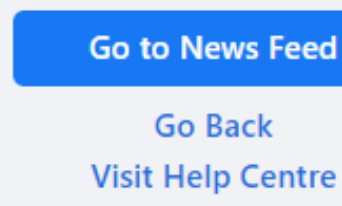

Fig. 2: Error message encountered by Australian Facebook users attempting to access any posts containing news content on Facebook, and by international users attempting to access Australian news content on Facebook

\title{
This post can't be shared
}

\begin{abstract}
In response to Australian government legislation, Facebook restricts the posting of news links and all posts from news Pages in Australia. Globally, the posting and sharing of news links from Australian publications is restricted.
\end{abstract}

Fig. 3: Error message preventing Australian and international Facebook users from sharing links to Australian news sites (Jones, 2021)

\section{Implementation and Impact of the Facebook News Ban}

Drawing on data from Facebook's own social media data service, CrowdTangle, this paper provides detailed evidence on the implementation and impact of Facebook's 'Australian news ban', as the week-long removal of domestic and international news content from the Australian segment of the global Facebook network has become known. During as well as after the ban - which began in the early hours of 18 February 2021, and ended on 26 February, several days after Facebook announced that it had reached an agreement with the Australian government that would adjust the provisions of the NMBC in its favour (Easton, 2021) - we gathered data on posting of and interactions with links to Australian news content on public pages, public groups, and public verified profiles on Facebook. To do so we drew on a list of the 39 leading Australian news domains (which, given the exceptionally concentrated Australian media 
market, covers the vast majority of the market), and queried CrowdTangle for any posts containing links to these domains, from Australia and beyond.

Fig. 4 shows a preliminary visualisation of these data for links to Australian news sites posted on Australian Facebook pages only; this uses CrowdTangle's classification of pages by country, which is based on the geographic location of the majority of the page administrators. It documents a substantial decline in the posting of links to Australian news sites from the early hours of 18 February, though curiously this decline remains incomplete for the following days: during daytime hours, Australian Facebook pages continue to post some 20-50 posts containing Australian news links per hour, and posting only ceases completely by midday on 23 February (after Facebook had already announced that it would lift its news ban; Easton, 2021). We speculate that this continued posting in the days immediately following the implementation of the ban may have resulted from experimentation with URL shorteners or posting from non-Australian administrator accounts - pathways which Facebook had not yet locked down entirely.

\section{Posts / interactions per hour, Australian Facebook pages only}

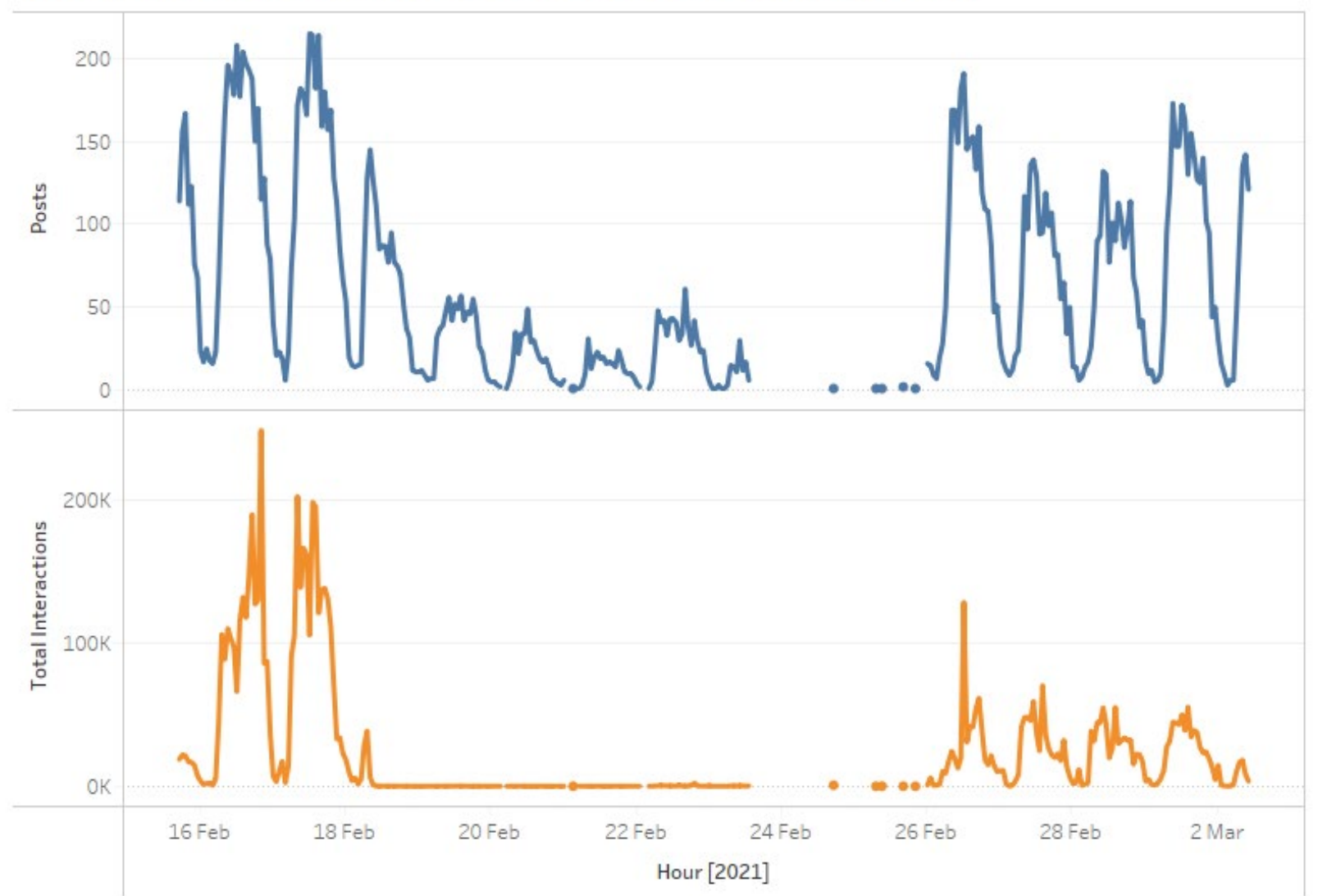

Fig. 4: Posts on Australian Facebook pages sharing links to Australian news media (blue), and total interactions with those posts (orange), per hour, 16 Feb. to 2 Mar. 2021

Even if some such posting continued to occur during the first days of the ban, however, these posts were all but invisible to Australian and international Facebook users, as fig. 4 also demonstrates: total interactions with those posts dropped to virtually zero from 09:00 on 18 February, and only recovered in the morning of 26 February, as the ban 
was officially lifted. At least in the first days after the lifting of the news ban, the total volume of interactions remained at a fraction of its pre-ban levels; it must be noted in this context, however, that interaction levels on the weekend days of 27 and 28 February should be expected to be lower than on weekdays. Finally, this lack of news visibility on Facebook also resulted in a precipitous drop in click-through rates to the news sites themselves, as research by $A B C$ News documents (Purtill, 2021).

Importantly, however, this impact was not limited to genuine Australian news providers: in its initial implementation of the news ban, Facebook also blocked the content of a broad range of other actors that it had classified as providing news-like content. This included, for instance, the pages of the Australian Bureau of Meteorology, of State Emergency Services, of small businesses and community organisations, and - most problematically during the COVID-19 pandemic - of federal and state health agencies providing critical information about local lockdowns, preventative measures, and vaccination planning. Remarkably, even Facebook's own official Facebook page was blocked (Taylor, 2021). Some such blocks were reversed fairly quickly, before the eventual conclusion of the news ban.

\section{Further Outlook}

Our further analysis of these developments for the full paper will examine these developments in greater detail, and explore in particular whether Australian Facebook users shifted their attention to other news sources (potentially including fringe outlets of questionable quality), and whether the week-long ban appears to have had any lasting impact on Australians' news engagement practices on the platform. We will also reflect on the resolution of the conflict between Facebook and the Australian government, assessing whether the outcome favours the interests of one side more than the other's.

\section{References}

$A B C$ News. (2021). Facebook Just Restricted Access to News in Australia: Here's What That Means for You. ABC News, 18 Feb. 2021. https://www.abc.net.au/news/2021-0218/facebook-news-ban-what-just-happened-post-zuckerberg/13166710

Blackiston, H. (2020). 'Ill-Timed and Misconceived': The Industry Responds to Facebook's Threat to Ban News in Australia. Mumbrella, 1 Sep. 2020. https://mumbrella.com.au/ill-timed-and-misconceived-the-industry-responds-tofacebooks-threat-to-ban-news-in-australia-641475

Easton, W. (2020). An Update about Changes to Facebook's Services in Australia. Facebook Newsroom, 31 Aug. 2020. https://about.fb.com/news/2020/08/changes-tofacebooks-services-in-australia/

- (2021). Changes to Sharing and Viewing News on Facebook in Australia. Facebook Newsroom, 22 Feb. 2021. https://about.fb.com/news/2021/02/changes-tosharing-and-viewing-news-on-facebook-in-australia/ 
Jones, T. (2021). How Australia's Facebook News Ban Will Impact You. Gizmodo, 18 Feb. 2021. https://www.gizmodo.com.au/2021/02/how-australias-facebook-news-banwill-impact-youl

Meade, A. (2020). Facebook Threatens to Block Australians from Sharing News in Battle over Landmark Media Law. The Guardian, 1 Sep. 2020.

https://www.theguardian.com/media/2020/sep/01/facebook-instagram-threatens-blockaustralians-sharing-news-landmark-accc-media-law

Purtill, J. (2021). These Graphs Tell the Story of the Facebook News Ban — and What Happened After. ABC News, 3 Mar. 2021. https://www.abc.net.au/news/science/202103-03/facebook-news-ban-australian-publisher-page-views-rebound/13206616

Taylor, J. (2021). Facebook's Botched Australia News Ban Hits Health Departments, Charities and Its Own Pages. The Guardian, 18 Feb. 2021.

https://www.theguardian.com/technology/2021/feb/18/facebook-blocks-healthdepartments-charities-and-its-own-pages-in-botched-australia-news-ban

Wakabayashi, D., \& Isaac, M. (2020). Facebook Could Block Sharing of News Stories in Australia. The New York Times, 31 Aug. 2020.

https://www.nytimes.com/2020/08/31/technology/facebook-block-news-storiesaustralia.html 


\title{
Paper 4
}

\section{A CODE WITHOUT A POINTY END: HAS THE NMBC WORKED WITHOUT DESIGNATION?}

\author{
Belinda Barnet \\ Swinburne University of Technology
}

The NMBC was legislated in Australian parliament on 26 February 2021 and the platforms were instructed to reach deals with all eligible Australian news outlets if they wanted to avoid being designated under it. Designation is the government's key bargaining chip: it is being used as leverage to make the platforms negotiate.

What "not designated" means in reality is that neither platform actually falls under the code yet. This is what both Google and Facebook wanted-a code that could not be enforced. In order to reach that prize they have to behave as though they are subject to the code. This sounds slightly ludicrous, but it has resulted in some very lucrative deals for Australian media outlets to date, which this paper examines, particularly from Google. Designation will be revisited later this year by the Treasurer and he will consider the deals each platform has reached in making his decision; specifically he will "consider whether the platform has made a significant contribution to the Australian news industry" (Snape 2021). The more deals and the more lucrative those deals are, the better.

This paper considers the progress so far, and which media companies have benefited. Have both platforms been negotiating in good faith? Has this code, on balance, been good for the media industry in Australia? Should the government designate one or both platforms?

If we are to "reward" one of the platforms for negotiating in good faith and consequently not name it, it would be Google. The two platforms responded very differently to the Government's request to make deals with media outlets. Google read the room: it quickly came out with a flurry of deals that were very beneficial for the Australian media industry, both big players like News Corporation and smaller publishers like The Guardian which has set up a small local operation in Australia that is editorially and financially independent from The Guardian UK. But Facebook has been dragging its feet. By all reports it has been offering fairly low-value deals to smaller media outlets. Google in fact started making deals before the legislation had even passed parliament.

The first deals announced by media outlets were with Google for our three largest publishers. Seven West, which owns the Seven TV network and The West Australian newspaper among other outlets, announced a $\$ 30$ million p.a. deal just before the legislation hit parliament (Samios \& Visentin, 2021), which will now be a significant portion of their annual income. The financial benefit here is undeniable. News Corporation followed with a "significant" multimillion dollar deal which is still undisclosed (Ward 2021), and Nine shortly after. Importantly, Google also cut a deal with Guardian 
Media in February for a very satisfying amount (Taylor 2021), which will enable them to employ dozens of new journalists in their newsrooms. This journalism, unlike News Corporation's, is already both free and open access.

Google went on to negotiate fairly quickly with smaller publishers and subscription news services as well: outlets like Junkee media and Crikey were in the bag before the code had even passed. It is also currently "on the brink of signing a lucrative deal for its journalism to appear in Google's Showcase" with our national broadcaster, the ABC (Meade 2021a). Despite being highly resistant to the bargaining code initially, Google appears to be negotiating in good faith. Some of this money will be a lifeline for newsrooms struggling around the county, and although there is no guarantee that the larger publishers will spend this new river of cash on actual journalism, it does provide some much-needed income going forward that will make the production of news content more attractive.

Facebook, however, have not been so cooperative. They refused to negotiate at all until they had assurance they may not be designated, and have been "freezing new publishers out" (Meade 2021b). Two weeks after the legislation passed the Australian parliament, they had still "failed to sign a single big media player" (Meade 2021b). They reached deals with Australia's largest media companies Nine, News Corp, and Seven West in February (Carrett 2021)—but no deals with Australian public broadcasters. They have signed letters of intent with smaller outlets like Private Media, publisher of Crikey, and Schwartz Media, which owns The Saturday Paper, but no formal contracts have been inked (Samios 2021b). It is important that Facebook negotiates fairly with smaller players to maintain a healthy media ecosystem.

Unpublished background information suggests that Facebook are currently negotiating with the $A B C$, and have offered one of our most prominent independent publishers (which cannot yet be named) a disappointingly small sum. This should be a warning sign. Many smaller outlets (and rural or regional outlets) have been unable to get through at all, and Facebook are not playing fair when they do get through. The ACCC is watching this quite closely, and it would be our recommendation if they continue to operate in this way that the Treasurer designate Facebook and not Google: Facebook are not treating smaller, rural, and independent outlets fairly.

Overall, then, the NMBC has enriched the Australian media industry: we have seen close to $\$ 100$ million secured from Google in particular as a result of it passing parliament. These funds were sorely needed and have come just in time: because game-changing sums have also gone to independent outlets like The Guardian as well as to the major publishers, they may reshape the Australian news industry and strengthen independent journalism and media diversity. The ultimate intention of the code was to benefit our news media industry in Australia and it has already been successful in this regard.

But the battle is not over: if either platform tries to skirt the code or ignore smaller publishers then they should be designated. At the moment, that means Facebook. 


\section{References}

Carrett, Joel. 2021. Seven West Media Announces News Agreement with Facebook. ABC News, 23 Feb. 2021. https://www.abc.net.au/news/2021-02-23/seven-west-medianews-agreement-facebook-media-bargaining-code/13185008

Meade, Amanda. 2021a. ABC Journalism to Appear on Google's News Showcase in Lucrative Deal. The Guardian, 23 Feb. 2021.

https://www.theguardian.com/media/2021/feb/23/abc-journalism-to-appear-on-googlesshowcase-in-lucrative-deal

Meade, Amanda. 2021b. Facebook News Ban Fears Grow as Tech Giant Fails to Sign Deals with Australia's Big Media Players. The Guardian, 11 Mar. 2021. https://www.theguardian.com/media/2021/mar/11/facebook-news-ban-fears-grow-astech-giant-fails-to-sign-deals-with-australias-big-media-players

Samios, Zoe. 2021a. News Corp Australia, Nine Strike Facebook Content Deals. Sydney Morning Herald, 16 Feb. 2021. https://www.smh.com.au/business/companies/news-corp-australia-signs-deal-withfacebook-20210316-p57b1f.html

Samios, Zoe. 2021b. Media Companies Look for Fix as Facebook Talks Falter. Sydney Morning Herald, 8 Mar. 2021. https://www.smh.com.au/business/companies/medialooks-for-fix-as-facebook-talks-falter-20210305-p5788x.html

Samios, Zoe, \& Visentin, Lisa. 2021. Google Closing In on News Content Deals with ABC, Nine, Guardian. Sydney Morning Herald, 15 Feb. 2021. https://www.smh.com.au/business/companies/seven-west-media-inks-30-million-a-yeargoogle-deal-20210215-p572iv.html

Snape, Jack. 2021. The Media Bargaining Code Has Passed Parliament, But Don't Rule Out Another Facebook News Ban Yet. ABC News, 25 Feb. 2021. https://www.abc.net.au/news/2021-02-24/news-media-bargaining-code-passesparliament-facebook-ban/13186354

Ward, Miranda 2021. News Corp Signs Partnership Deal with Google. Australian Financial Review, 15 Feb. 2021. https://www.afr.com/companies/media-andmarketing/news-corp-signs-news-partnership-deal-with-google-20210218-p573ja 